\title{
Comprehensive detection and identification of bacterial DNA in the blood of patients with sepsis and healthy volunteers using next-generation sequencing method - the observation of DNAemia
}

\author{
T. Gosiewski ${ }^{1}$ - A. H. Ludwig-Galezowska ${ }^{2}$ K. Huminska ${ }^{3,4}$ - A. Sroka-Oleksiak ${ }^{1}$. \\ P. Radkowski $^{2}$ - D. Salamon ${ }^{1}$ - J. Wojciechowicz ${ }^{3}$ - M. Kus-Slowinska ${ }^{3} \cdot$ M. Bulanda ${ }^{1}$. \\ P. P. Wolkow ${ }^{2}$ (D)
}

Received: 30 June 2016 / Accepted: 26 September 2016 /Published online: 22 October 2016

(C) The Author(s) 2016. This article is published with open access at Springerlink.com

\begin{abstract}
Blood is considered to be a sterile microenvironment, in which bacteria appear only periodically. Previously used methods allowed only for the detection of either viable bacteria with low sensitivity or selected species of bacteria. The NextGeneration Sequencing method (NGS) enables the identification of all bacteria in the sample with their taxonomic classification. We used NGS for the analysis of blood samples from healthy volunteers $(n=23)$ and patients with sepsis $(n=62)$ to check whether any bacterial DNA exists in the blood of healthy people and to identify bacterial taxonomic profile in the blood of septic patients. The presence of bacterial DNA was found both in septic and healthy subjects; however, bacterial diversity was significantly different $(P=0.002)$ between the studied groups. Among healthy volunteers, a significant predominance of
\end{abstract}

Tomasz Gosiewski and Agnieszka H. Ludwig-Galezowska contributed equally to this work.

Tomasz Gosiewski and Agnieszka H. Ludwig-Galezowska considered as first co-authors.

Electronic supplementary material The online version of this article (doi:10.1007/s10096-016-2805-7) contains supplementary material, which is available to authorized users.

\section{P. P. Wolkow}

pawel.wolkow@uj.edu.pl

1 Department of Microbiology, Jagiellonian University Medical College, Krakow, Poland

2 Center for Medical Genomics OMICRON, Jagiellonian University Medical College, 7C Kopernika Str., 31-034 Krakow, Poland

3 Genomic Laboratory, DNA Research Center, Poznan, Poland

4 Laboratory of High Throughput Technologies, Institute of Molecular Biology and Biotechnology, Faculty of Biology, Adam Mickiewicz University, Poznan, Poland anaerobic bacteria (76.2\%), of which most were bacteria of the order Bifidobacteriales (73.0\%), was observed. In sepsis, the majority of detected taxa belonged to aerobic or microaerophilic microorganisms $(75.1 \%)$. The most striking difference was seen in the case of Actinobacteria phyla, the abundance of which was decreased in sepsis $(P<0.001)$ and Proteobacteria phyla which was decreased in the healthy volunteers $(P<0.001)$. Our research shows that bacterial DNA can be detected in the blood of healthy people and that its taxonomic composition is different from the one seen in septic patients. Detection of bacterial DNA in the blood of healthy people may suggest that bacteria continuously translocate into the blood, but not always cause sepsis; this observation can be called DNAemia.

\section{Introduction}

The human body is naturally colonized by bacteria, viruses and fungi which occur in specific locations such as the gastrointestinal tract, skin and vagina. However, according to the state of knowledge based on microbial culture, rather than next generation sequencing, most areas inside of the body in healthy man are physiologically sterile [1]. An example of such a sterile microenvironment would be blood, in which bacteria (microorganisms) appear only periodically, e.g. during sepsis. Some researchers have suggested that perhaps in the blood of healthy people traces of bacteria can be found [2]. An example would be asymptomatic bacteraemia, which sometimes occurs as a result of dental procedures, e.g. tooth extraction or orthodontic procedures $[3,4]$. However, it is generally agreed that bacteria must be rapidly eliminated from the bloodstream.

The gold standard to diagnose bacteraemia is blood culture using special media, preferably in automatic culture systems, 
e.g. BACTEC (BectonDickinson). The advantages of this method are the ease of use and low cost of an examination. The disadvantages are its duration, spanning even up to 5 days (until issue of the results) and suboptimal sensitivity, which causes only $15-20 \%$ cultures to have a positive microbial growth $[5,6]$. In addition, blood culture method detects only viable bacterial cells. There are also few molecular, cultureindependent methods, such as PCR or FISH (Fluorescent In Situ Hybridization), that enable the detection of selected species of bacteria based on the presence of their DNA [7, 8]. These techniques are very sensitive and allow for quick detection of even a very low number of microorganisms in the samples. They have also been commercially adopted to create diagnostic kits, e.g. SeptiFast (Roche), SeptiTest (Molzym), or VYOO (SIRS-Lab); however, they enable detection of only selected species or groups of microorganisms [7]. None of the above-mentioned methods allows to assess the frequency and taxonomical diversity of bacteraemia.

More recently, Next-Generation Sequencing (NGS), which enables the identification of all species of bacteria with their taxonomic classification, was introduced. This method has been successfully applied to a detailed analysis of the human and animal microbiome as well as environmental samples, e.g. soil and seawater [9-11]. Since this method allows to obtain knowledge about all bacteria present in the sample, we can ask: (1) what bacteria exist in the blood of patients with clinical symptoms of SIRS (systemic inflammatory response syndrome), which have not been detected by available diagnostic methods and (2) whether any bacterial DNA is present in the blood of healthy volunteers. There has been no description of the tests carried out using NGS for the analysis of blood from healthy volunteers and sepsis patients yet.

In this study, we describe the results of the application of NGS for the analysis of blood samples from healthy volunteers, compared to patients with clinical symptoms of sepsis.

\section{Materials and methods}

Samples Eighty five blood samples were included in this study. Sixty two were from patients hospitalized in the John Paul II Hospital in Krakow at The Ward of Anesthesiology and Intensive Care. They underwent serious cardiac surgical procedures and had clinical symptoms of sepsis according to criteria of the Society of Critical Care Medicine (SCCM) and The European Society of Intensive Care Medicine (ESICM) [12]. The median age of these patients was 67 years. Among them 14 were female and 48 were male. Twenty three blood samples were collected from healthy volunteers who had no clinical symptoms of sepsis and no elevated level of inflammatory markers (CRP, OB). The median age of healthy subjects was 59 years. Among them 13 were female and 10 were male. No patient or volunteer was treated with antibiotics before the collection of blood samples. Blood samples were drawn into 4-ml Vacutainer K3E (BectonDickinson) test tubes.

Sample analysis Each of the samples underwent two methods of analysis - microbiological culture and NGS.

Microbiological culture Routine blood culture was carried out in the John Paul II Hospital in Krakow in the Microbiology Department using BacT/ALERT® 3D apparatus (bioMérieux).

DNA isolation, quantitation and quantification Microbial DNA was isolated from $1.5-\mathrm{ml}$ of blood sample according to the method described by Gosiewski et al. with the employment of a ready-to-use Blood Mini kit (A\&A Biotechnology) [13].

The concentration and purity of total DNA isolates in the samples were measured spectrophotometrically (NanoDrop, Thermo Scientific) at wavelengths of A260 and A280.

16S Library preparation and sequencing The library preparation procedure followed the 16S Metagenomic Sequencing Library Preparation Protocol - Preparing 16S Ribosomal RNA Gene Amplicons for the Illumina MiSeq System (Illumina). DNA amplification was performed with the use of KAPA HiFi HotStart ReadyMix kit (KAPA BIOSYSTEMS) on C100 thermal cycler (BioRad), as a nested PCR. The content of PCR reaction mix was the following: 1st amplificationDNA template $(2.5 \mu \mathrm{l})$, each $1 \mu \mathrm{M}$ external primers $(5.0 \mu \mathrm{l})$, KAPA HiFi HotStart ReadyMix (12.5 $\mu \mathrm{l})$; 2nd amplification-DNA amplicon $(2.5 \mu \mathrm{l})$, each $1 \mu \mathrm{M}$ internal primers $(5.0 \mu \mathrm{l})$, KAPA HiFi HotStart ReadyMix $(12.5 \mu \mathrm{l})$.

Amplification of hypervariable regions (V3 and V4) of $16 \mathrm{~S}$ rRNA was used to characterize taxonomic diversity present in blood samples. The universal external primers (Table 1) were designed by aligning to the conservative regions $\mathrm{V} 3$ and $\mathrm{V} 4$ of 16S rDNA using the procedure described by Gosiewski et al. [14]. A nested amplification was performed using PCR product from the first reaction as a template- the V3 and V4 regions were amplified with region-specific internal primers [15] that included the MiSeq flowcell (Illumina) overhang adapter sequences attached to the $5^{\prime}$ end of primer (Table 1). Further, the 16S library was purified, samples were indexed, amplicon concentrations were quantified and samples were pooled. DNA library concentration was quantified using PicoGreen (Life Technologies).

Negative control (NTC) Five samples of sterile water were used as a control of purity of DNA libraries.

NGS sequencing The $10 \mathrm{pM}$ library containing 90 pooled indexed samples with $20 \%$ spike-in PhiX control DNA was loaded onto the MiSeq (Illumina) apparatus. Sequencing was performed using the MiSeq Reagent Kit v3 (600 cycles). The 
Table 1 Sequences of primers and probes utilized in the study

\begin{tabular}{|c|c|c|c|c|c|c|c|c|c|}
\hline Amplification & Primer & Sequence $5^{\prime}-3^{\prime}$ & Origin & Target sequences & \multicolumn{5}{|c|}{ Amplification program } \\
\hline External & $\begin{array}{l}\mathrm{F} \\
\mathrm{R}\end{array}$ & $\begin{array}{l}\text { ACGGCCNNRACTCCTAC } \\
\text { TTACGGNNTGGACTACHV }\end{array}$ & This study & $\begin{array}{l}\mathrm{V} 3 \text { and V4 } \\
16 \mathrm{~S} \text { rRNA }\end{array}$ & $\begin{array}{l}95^{\mathrm{O}} \\
95^{\mathrm{O}} \\
48^{\mathrm{O}} \\
72^{\mathrm{O}} \\
72^{\mathrm{O}}\end{array}$ & $\begin{array}{c}\mathrm{C} \\
\mathrm{C} \\
\mathrm{C} \\
\mathrm{C} \\
\mathrm{C}\end{array}$ & $\begin{array}{l}-\quad 5 \\
-\quad 15 \\
-\quad 20 \\
-\quad 30 \\
-\quad 5\end{array}$ & $\begin{array}{l}\min \\
\mathrm{sec} \\
\mathrm{sec} \\
\mathrm{sec} \\
\mathrm{min}\end{array}$ & $20 \times$ \\
\hline Internal & $\begin{array}{l}\mathrm{F} \\
\mathrm{R}\end{array}$ & $\begin{array}{l}\text { CCTACGGGNGGCWGCAG } \\
\text { GACTACHVGGGTATCTAATCC }\end{array}$ & {$[15]$} & & $95^{\mathrm{O}}$ & $\mathrm{C}$ & -5 & $\min$ & \\
\hline Overhang adapters $^{\mathrm{a}}$ & $\mathrm{F}$ & $\begin{array}{l}\text { TCGTCGGCAGCGTCAGATGT } \\
\text { GTATAAGAGACAG } \\
\text { GTCTCGTGGGCTCGGAGATG } \\
\text { TGTATAAGAGACAG }\end{array}$ & Illumina & & $\begin{array}{l}95^{\mathrm{O}} \\
55^{\mathrm{O}} \\
72^{\mathrm{O}} \\
72^{\mathrm{O}}\end{array}$ & $\begin{array}{l}\mathrm{C} \\
\mathrm{C} \\
\mathrm{C} \\
\mathrm{C}\end{array}$ & $\begin{array}{l}-\quad 30 \\
-\quad 30 \\
-\quad 30 \\
-\quad 5\end{array}$ & $\begin{array}{c}\mathrm{sec} \\
\mathrm{sec} \\
\mathrm{sec} \\
\mathrm{min}\end{array}$ & $30 \times$ \\
\hline
\end{tabular}

${ }^{\text {a }}$ The overhang adapter sequences were added to the internal primer attached to the $5^{\prime}$ end

sequencing procedure was performed in the Genomic Laboratory of the DNA Research Center (Centrum Badań DNA), Poznan, Poland.

Data analysis and statistics Sample quality was evaluated using FastQC tool. PCR primers and sequencing adapters were trimmed using the Cutadapt package. Resulting short reads where joined on overlapping regions using the fastq-join tool from the ea-utils package. Both joined and forward unjoined reads were used for further analysis. Reads with base quality lower than 20 were filtered out. OTUs were picked using open-reference protocol. In the first step, closed reference OTU picking is done against the Green Genes 13.08 reference database. The remaining reads that failed to hit the reference database were filtered out and used to perform de novo OTU picking. Reads were clustered using uclust. Taxonomy assignments were performed with PyNAST. Singleton OTUs were removed before further analyses. Relative OTU abundances were calculated using QIIME (www.qiime.org). To estimate alpha diversity chao1, observed OTUs and phylogenetic distance metrics were calculated. Both weighted and unweighted UniFrac distances were calculated to analyze beta diversity, using Student's t-test. Results were transformed using PCoA and visualized with Emperor. Frequency of OTUs across sample groups was compared using non-parametric ANOVA (Kruskal-Wallis test). Differential abundance of OTUs across sample groups was analyzed using DESeq2 (negative binomial Wald test).

\section{Results}

\section{Blood culture results}

Nineteen out of $62(30.6 \%)$ blood samples from patients with clinical symptoms of sepsis were positive when analyzed by microbiological culture. In all but three samples from septic patients, the results of blood culture were concordant with the results of next generation sequencing on the genus level. All 23 samples (100\%) collected from volunteers were negative.

\section{Metagenomic sequencing of the blood microbiome}

A total of 4,933,386 reads were generated for the blood microbiome without any unassigned sequences. The minimal number of reads per sample was 59 (maximal 358,089; average 46,133). Samples with less than 10,000 reads (6 out of $62 ; 9.67 \%$ ) were excluded from the analysis.

The presence of bacterial DNA was found in all tested blood samples. Number of reads was comparable between healthy and sepsis; however, bacterial diversity was significantly different $(p=0.002)$ as shown by PD whole tree (Fig. 1), where samples from healthy volunteers were more diverse than sepsis samples. This was not seen when

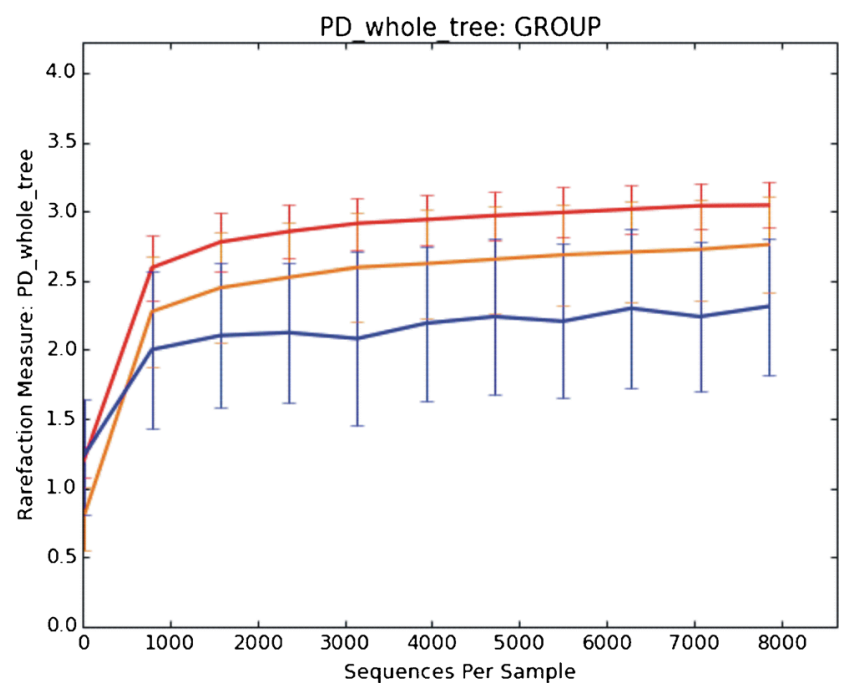

Fig. 1 Rarefaction curves for patients with sepsis (orange curve) versus healthy patients (red curve) and NTC samples (blue curve); $p=0.002$ 
Chaol or Number of Operational Taxonomic Units metrics were used.

Beta diversity as analyzed both by weighted and unweighted UniFrac, showed significant differences between healthy volunteers and sepsis patients $(P<0.001)$. There was a clear clustering of those who had sepsis and those who were healthy on PCoA (Fig. 2).

In general, differences were observed in the quantitative composition of bacterial taxon between the groups of healthy volunteers and patients with sepsis. Actinobacteria phyla abundance was decreased in the sepsis group (from $76.3 \%$ for healthy volunteers to $31.0 \%$ for sepsis group) $(P<0.001)$ (Fig. 3), while Proteobacteria phyla abundance was increased (healthy $16.4 \%$, sepsis $60.1 \%$; $P<0.001$ ) (Fig. 3).

Most sequences from Proteobacteria phylum belonged to the following orders: Pseudomonadales (7.2\% vs $4.9 \%$; $P=0.01)$; Rhizobiales $(6.2 \%$ vs $39.3 \% ; P<0.001)$; Enterobacteriales ( $0.2 \%$ vs $3.0 \% ; P=0.56$ ); Aeromonadales (0.1\% vs $2.1 \%$; $P<0.001)$; Bacillales ( $1.6 \%$ vs $3.0 \%$; statistically insignificant) and Sphingomonadales (0.8\% vs $7.5 \%$; $P<0.001)$ in the healthy volunteers and in the sepsis group, respectively (Fig. 4). Actinobacteria phylum predominantly followed orders Bifidobacteriales $(73.0 \%$ vs $1.3 \%$; $P<0.001)$ and Actinomycetales ( $3.2 \%$ vs $29.3 \% ; P<0.001)$ in the healthy volunteers and in the septic patients.

In the healthy volunteers, a significant predominance of anaerobic bacteria $(76.2 \%)$, of which most were bacteria of the order Bifidobacteriales (73.0 \%), was observed. In the sepsis group most of the detected taxa belonged to aerobic or microaerophilic microorganisms $(75.1 \%)$, i.e. Pseudomonadales, Rhizobiales, Enterobacteriales, Aeromonadales, Bacillales and Sphingomonadales and Cellulosimicrobium genus (15.3\% vs $0 \%$ in healthy volunteers; $P<0.001)$.

After NTC libraries amplification there was very weak trace of the product on electrophoretic gel (Fig. 5). Of the five NTC samples, three had more than 10,000 reads (the most 54,550 reads). Their quantitative and qualitative taxonomic compositions were completely

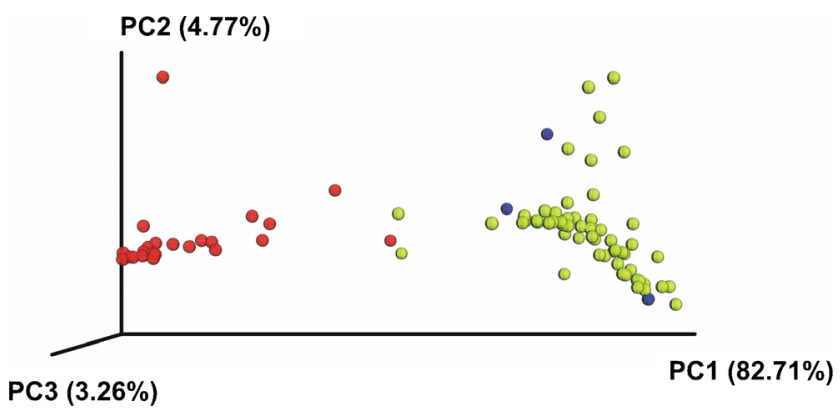

Fig. 2 Weighted UniFrac PCoA plot derived from NGS sequencing of blood samples taken from healthy volunteers $(n=23$, red), NTC samples (blue) and patients with sepsis $(n=62$, yellow) different from other samples included in the study (see Figs. 3 and 4).

\section{Discussion}

Until recently, molecular biology methods did not allow highthroughput taxonomic classification of bacteria, based on the analysis of their DNA. Development of NGS enabled a thorough investigation of microbial colonization at various body locations. This new technique answers previously unsolved questions, e.g. what kind of bacteria are present in the blood of sepsis patients for whom both culture-dependent and culture-independent methods gave mutually exclusive results or no results at all. Can we find microbial DNA in the blood of healthy people? If the answer to the previous question is positive, which taxonomic unit of bacteria does it come from? As NGS allows to gain a comprehensive profile of bacteria, to the best of our knowledge, we used it for the first time to examine blood samples from patients with clinical signs of sepsis and from healthy volunteers. The NGS method revealed the presence of bacterial DNA in all cases, including blood samples taken from healthy volunteers. However, bacterial diversity was significantly different between healthy and septic subjects (Figs. 1 and 2).

It has been shown by Fitting et al. using PCR method that bacterial DNA can appear in the patients' blood, even if they have non-infectious SIRS [16]. Similar results obtained using SeptiFast test (Roche) demonstrated the presence of bacteria in $75 \%$ of analyzed blood samples [17]. Gosiewski et al., thanks to the nested PCR method, indicated that $71.8 \%$ of analyzed samples tested positive for bacterial presence [8].

Nikkari et al. indicated the presence of bacterial DNA by PCR in the blood of healthy people [2]. This might be a result of physiological translocation of bacteria from the gastrointestinal tract or the oral cavity or from outside of the body, which however, did not induce sepsis due to the efficient functioning of the immune system $[3,18,19]$. Until now two reports on usage of NGS for detection of bacteraemia in patients' blood but without symptoms of sepsis were published, namely, after tooth extraction [3] and in AIDS patients [18].

Here, by using NGS, we (1) demonstrate the presence of bacterial DNA in the blood of healthy people and (2) show different quantitative taxonomic composition of bacterial DNA in patients with sepsis compared to healthy volunteers at all taxonomic levels (Figs. 3 and 4). At the level of bacterial phyla we observed a significant decrease in the proportion of Actinobacteria, while the percentage of Proteobacteria increased in the sepsis group (Fig. 1). Aerobic and microaerophilic bacteria $(75.1 \%)$ dominated in patients. Within these, one could see mainly bacteria that often exist in the hospital environment, like Pseudomonadales, Enterobacteriales, Bacillales orders and which are typically 
a

Effect of patients status on taxonomy composition of phyla abundances

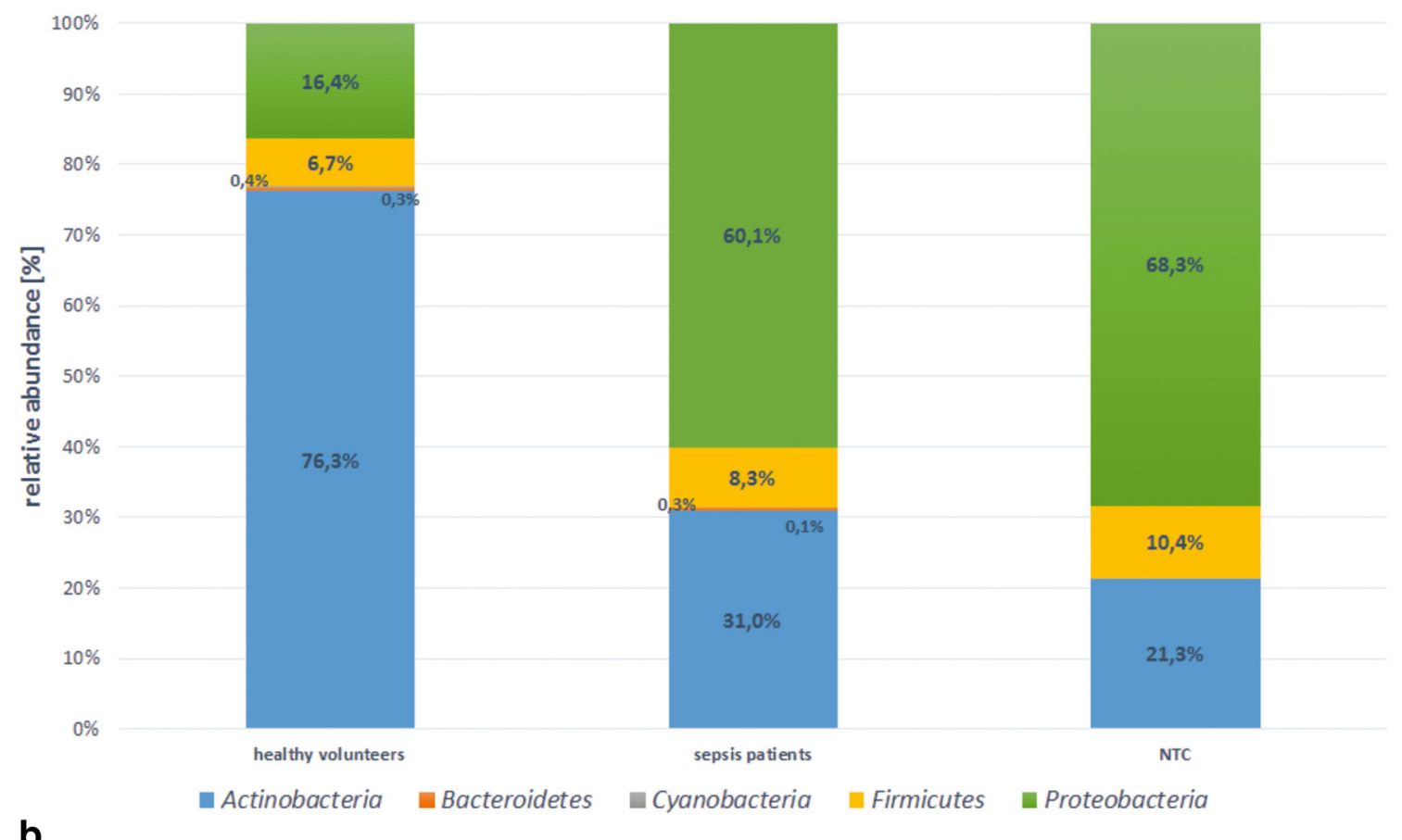

b

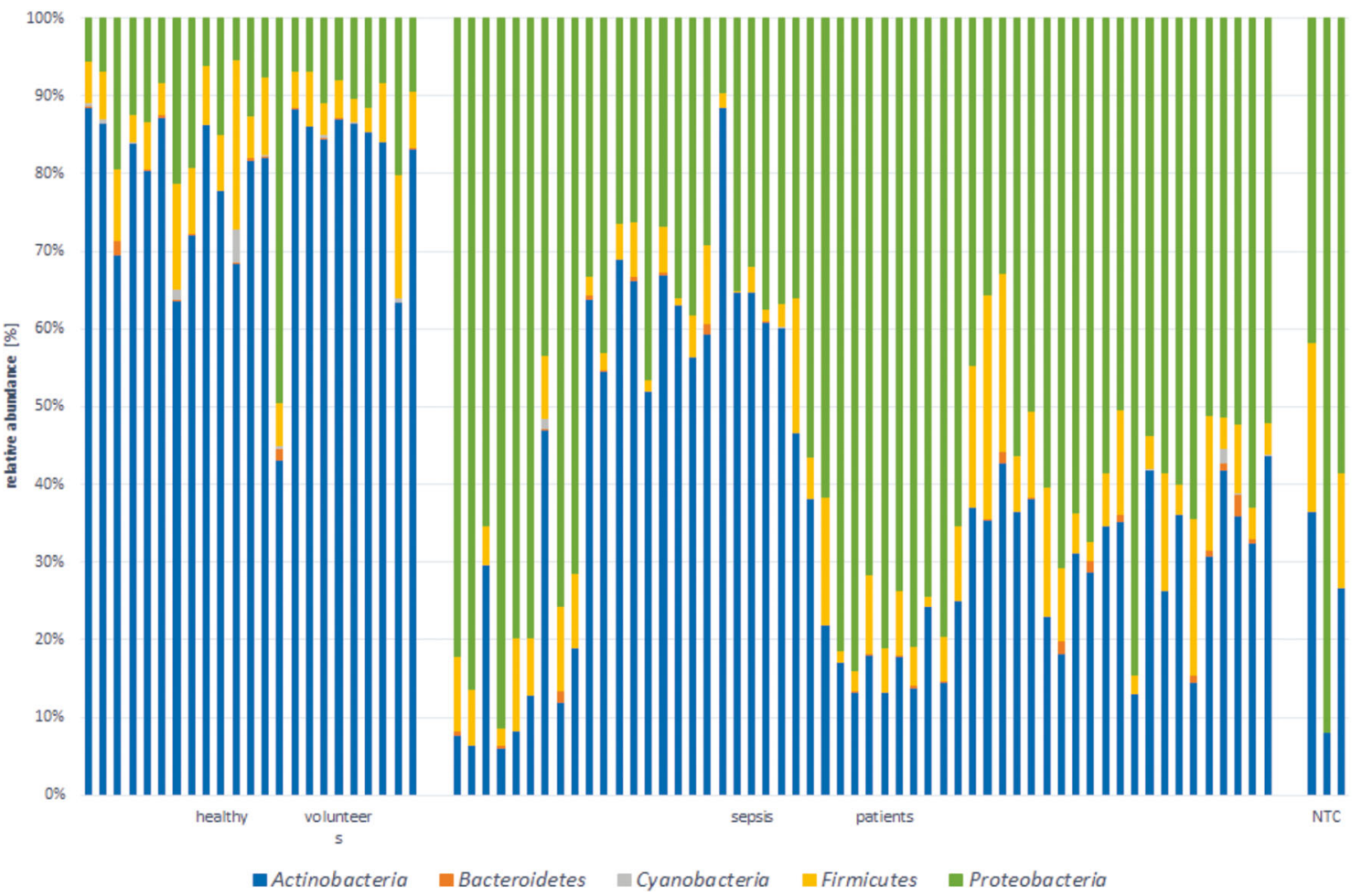

Fig. 3 Phyla abundances in the studied groups

known to cause sepsis [20,21]. Less common were bacteria belonging to the Sphingomonadales order and Cellulosimicrobium genus (within Actinomycetales order), however, in the literature investigators described cases of bacteraemia caused also by these taxa [22-24]. The most surprising was the fact that in the blood of patients with sepsis we detected DNA of Rhizobiales order which fix nitrogen and are symbiotic with plant roots. The occurrence of these bacteria could suggest cross-contamination of samples, but there were significant differences between sepsis patients and 


\section{Effect of patients status on taxonomy composition of order abundances}

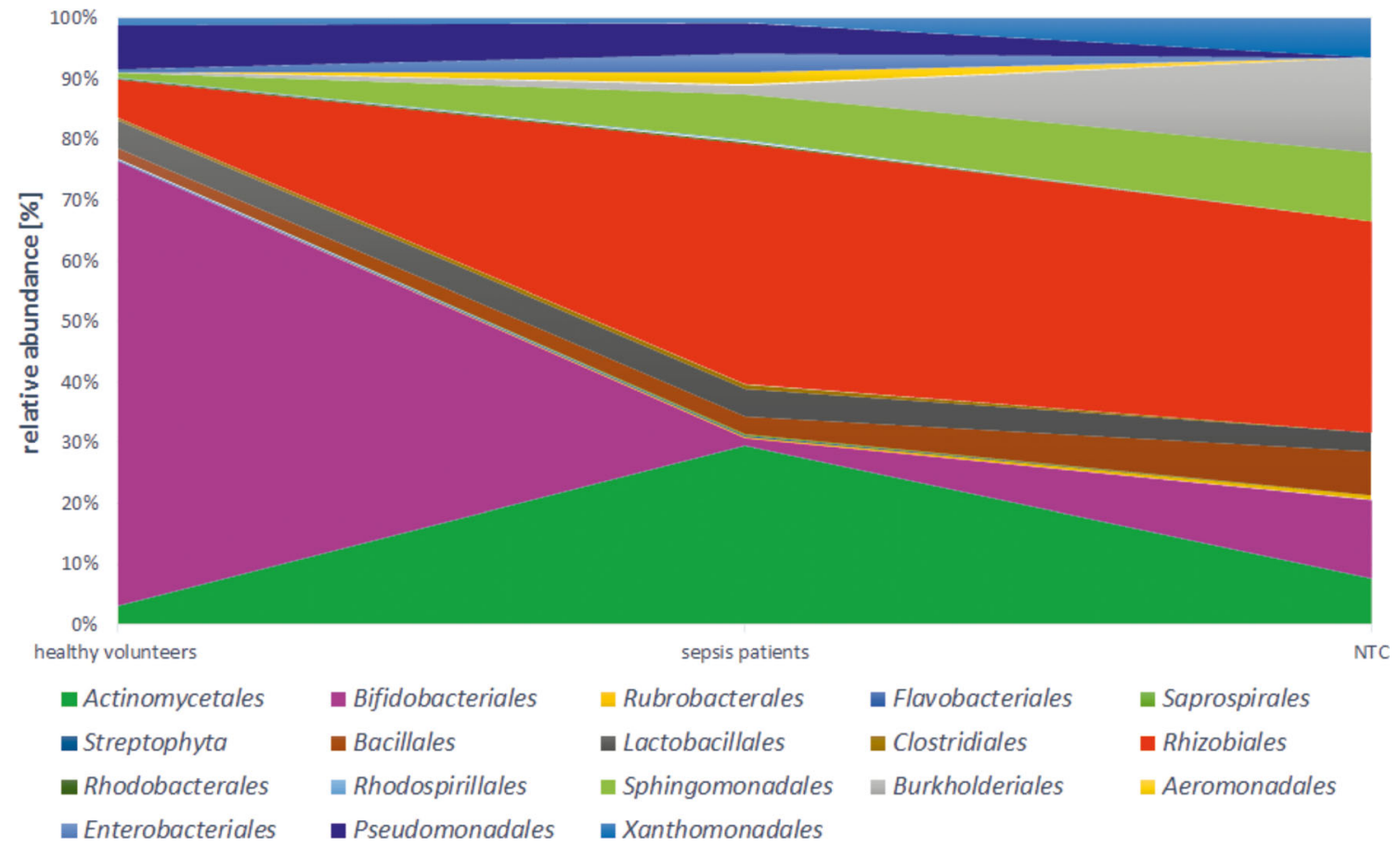

Fig. 4 Effect of patients status on taxonomy composition of order abundances

healthy volunteers $(39.3 \%$ vs $6.2 \% ; P<0.001)$ which makes explanation by contamination less plausible. Moreover, Lo at al. showed Rhizobiales in the blood of patients with fatal pulmonary illness so they can really be causative to the disease $[25,26]$. Moreover, no amplification products in the NTC samples can also be used as an evidence for the lack of contamination (Fig. 5). Even though, after sequencing, three samples obtained a sufficient number of reads for further analysis, it was probably the result of amplification during the indexing process. It is known that there are common pollutants of NTC samples that can be detected by NGS. They were listed by Salter et al. [27]. In our study, the most abundant pollutant was Sphingomonas genus (7.3\%). According to Laurence et al. the most frequent genus detected in NTC samples was Bradyrhizobium, which in our study was indicated at the level of $1.8 \%$ [28].

Blood of the healthy volunteers was dominated by bacterial DNA of the anaerobic Bifidobacteriales order (73.0 \%) (Fig. 2). Bacteria of this group are part of the human intestinal microbiota and they were reported to have immunomodulatory properties which could potentially prevent infection [29-31]. Shimizu et al. showed that the numbers of total obligate anaerobes and Bifidobacterium were severely decreased in patients with major burns and progressed sepsis [32]. Additionally, it was demonstrated in a mouse model, that colonization of both the caecum and the colon by Bifidobacteria led to a lesser bacterial contamination of the blood, the liver and the lungs by pathogenic bacteria [33].

In our study we showed a decrease of Bifibobacteria and increase of Proteobacteria DNA in patients with sepsis, which may be associated with impairment of the intestinal barrier and bacterial translocation [34, 35]. Patients hospitalized in the ICU ward (Intensive Care Unit) in whom the immune system had not worked properly were exposed to nosocomial bacteria, mainly from the hospital environment and from the patient's own skin microbiota, becoming opportunistic after surgery or other procedures that compromise the protective skin barrier and was reflected in the profile of bacterial DNA (Figs. 1 and 2).
Fig. 5 Representative results of nested amplification of the $16 \mathrm{~S}$ libraries and the negative control (NTC). Amplicon 550 bp

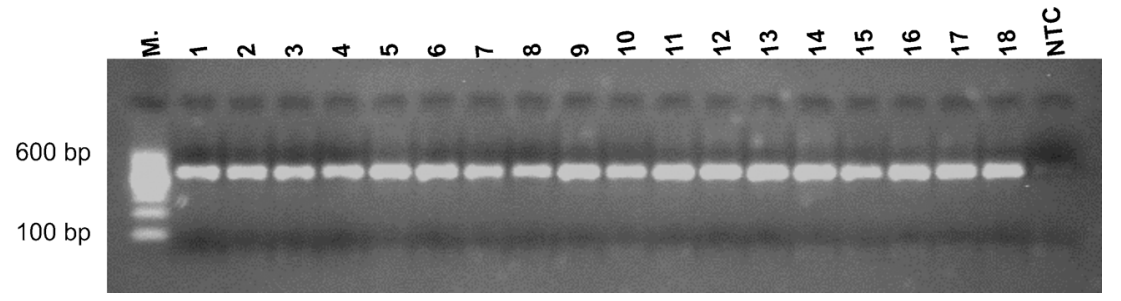


Obtained results show that NGS opens new perspectives in high-throughput microbial diagnostics at many phyla levels. Our research showed that bacteria might continuously translocate into the blood, but not always cause sepsis; this observation can be called DNAemia.

Acknowledgments This work was supported by Genomic Laboratory, DNA Research Center, Poznan, Poland, which financed and carried out the NGS sequencing.

Publication was supported by the Faculty of Medicine of Jagiellonian University Medical College (Leading National Research Centre 20122017).

\section{Compliance with ethical standards}

Conflicts of interest The authors declare no conflicts of interest.

Ethical approval All procedures performed in studies involving human participants were in accordance with the ethical standards of the institutional and/or national research committee and with the 1964 Helsinki declaration and its later amendments or comparable ethical standards. The research was granted approval by the local Bioethics Committee of the Jagiellonian University (KBET/94/B/2009). Written informed consent was obtained from participants before their enrollment in the study.

Open Access This article is distributed under the terms of the Creative Commons Attribution 4.0 International License (http:// creativecommons.org/licenses/by/4.0/), which permits unrestricted use, distribution, and reproduction in any medium, provided you give appropriate credit to the original author(s) and the source, provide a link to the Creative Commons license, and indicate if changes were made.

\section{References}

1. Zhu L, Lv H, Wang Y, Yang J, Ni B, Meng Z (2013) Microbial screening of unrelated cord blood units in a Chinese cord blood bank. Transfus Med 23(6):438-41. doi:10.1111/tme.12079

2. Nikkari S, McLaughlin IJ, Bi W, Dodge DE, Relman DA (2001) Does blood of healthy subjects contain bacterial ribosomal DNA? J Clin Microbiol 39:1956-9. doi:10.1128/JCM.39.5.1956-1959.2001

3. Benítez-Páez A, Álvarez M, Belda-Ferre P, Rubido S, Mira A, Tomás I (2013) Detection of transient bacteraemia following dental extractions by $16 \mathrm{~S}$ rDNA pyrosequencing: a pilot study. PLoS One. doi:10.1371/journal.pone.0057782

4. Umeh OD, Sanu OO, Utomi IL, Nwaokorie FO (2016) Prevalence and intensity of bacteraemia following orthodontic procedures. Int Orthod / Coll Eur Orthod 14:80-94. doi:10.1016/j. ortho.2015.12.001

5. Jamal W, Tamaray G, Pazhoor A, Rotimi VO (2006) Comparative evaluation of BacT/ALERT 3D and BACTEC systems for the recovery of pathogens causing bloodstream infections. Med Princ Pract 15:223-7. doi:10.1159/000092186

6. Loonen AJM, Wolffs PFG, Bruggeman CA, van den Brule AJC (2014) Developments for improved diagnosis of bacterial bloodstream infections. Eur J Clin Microbiol Infect Dis 33(10):16871702. doi:10.1007/s10096-014-2153-4

7. Skvarc M, Stubljar D, Rogina P, Kaasch AJ (2013) Non-culturebased methods to diagnose bloodstream infection: does it work? Eur J Microbiol Immunol (Bp) 3:97-104. doi:10.1556/EuJMI. 3.2013.2.2
8. Gosiewski T, Flis A, Sroka A, Kedzierska A, Pietrzyk A, Kedzierska J et al (2014) Comparison of nested, multiplex, qPCR; FISH; SeptiFast and blood culture methods in detection and identification of bacteria and fungi in blood of patients with sepsis. BMC Microbiol 14:2323. doi:10.1186/s12866-014-0313-4

9. Lladó S, Covino S, Solanas AM, Petruccioli M, D'annibale A, Viñas M (2015) Pyrosequencing reveals the effect of mobilizing agents and lignocellulosic substrate amendment on microbial community composition in a real industrial PAH-polluted soil. J Hazard Mater 283:35-43. doi:10.1016/j.jhazmat.2014.08.065

10. Knief C (2014) Analysis of plant microbe interactions in the era of next generation sequencing technologies. Front Plant Sci 5:216. doi:10.3389/fpls.2014.00216

11. Sassoubre LM, Yamahara KM, Boehm AB (2015) Temporal stability of the microbial community in sewage-polluted seawater exposed to natural sunlight cycles and marine microbiota. Appl Environ Microbiol 81:2107-16. doi:10.1128/AEM.03950-14

12. Dellinger RP, Levy MM, Rhodes A, Annane D, Gerlach H, Opal SM et al (2013) Surviving sepsis campaign: international guidelines for management of severe sepsis and septic shock: 2012. Crit Care Med 41:580-637. doi:10.1097/CCM.0b013e31827e83af

13. Gosiewski T, Szała L, Pietrzyk A, Brzychczy-Włoch M, Heczko PB, Bulanda M (2014) Comparison of methods for isolation of bacterial and fungal DNA from human blood. Curr Microbiol 68: 149-55. doi:10.1007/s00284-013-0451-1

14. Gosiewski T, Jurkiewicz-Badacz D, Sroka A, Brzychczy-Włoch M, Bulanda M (2014) A novel, nested, multiplex, real-time PCR for detection of bacteria and fungi in blood. BMC Microbiol 14:144. doi:10.1186/1471-2180-14-144

15. Klindworth A, Pruesse E, Schweer T, Peplies J, Quast C, Horn M et al (2013) Evaluation of general 16S ribosomal RNA gene PCR primers for classical and next-generation sequencing-based diversity studies. Nucleic Acids Res 41(1):e1. doi:10.1093/nar/gks808

16. Fitting C, Parlato M, Adib-Conquy M, Memain N, Philippart F, Misset B et al (2012) DNAemia detection by multiplex PCR and biomarkers for infection in systemic inflammatory response syndrome patients. PLoS One 7(6):e38916. doi:10.1371/journal. pone.0038916

17. Chang S-S, Hsieh W-H, Liu T-S, Lee S-H, Wang C-H, Chou H-C et al (2013) Multiplex PCR system for rapid detection of pathogens in patients with presumed sepsis - a systemic review and metaanalysis. PLoS One 8(5):e62323. doi:10.1371/journal. pone. 0062323

18. Li S-K, Leung RK-K, Guo H-X, Wei J-F, Wang J-H, Kwong K-T et al (2012) Detection and identification of plasma bacterial and viral elements in HIV/AIDS patients in comparison to healthy adults. Clin Microbiol Infect 18:1126-33. doi:10.1111/j.14690691.2011.03690.x

19. Sarac F, Salman T, Gun F, Celik A, Gurler N, Abbasoglu SD et al (2015) Effect of probiotic supplementation on bacterial translocation in common bile duct obstruction. Pediatr Surg Int 31:155-61. doi:10.1007/s00383-014-3643-2

20. Lai CC, Chen YH, Lin SH, Chung KP, Sheng WH, Ko WC et al (2014) Changing aetiology of healthcare-associated bloodstream infections at three medical centres in Taiwan, 2000-2011. Epidemiol Infect 142:2180-5. doi:10.1017/S0950268813003166

21. Wójkowska-Mach J, Baran M, Drwiła R, Ziętkiewicz M, Foryciarz E, Synowiec E et al (2012) Factors influencing the occurence of nosocomial bloodstream infections observed in thoracic and cardiosurgical postoperative care units. Anaesth Intensive Ther 44:16-20

22. Nandy S, Dudeja M, Das AK, Tiwari R (2013) Community acquired bacteremia by sphingomonas paucimobilis: two rare case reports. J Clin Diagn Res 7:2947-9. doi:10.7860/JCDR/ 2013/6459.3802 
23. Lin J-N, Lai C-H, Chen Y-H, Lin H-L, Huang C-K, Chen W-F et al (2010) Sphingomonas paucimobilis bacteremia in humans: 16 case reports and a literature review. J Microbiol Immunol Infect 43:3542. doi:10.1016/S1684-1182(10)60005-9

24. Rowlinson M-C, Bruckner DA, Hinnebusch C, Nielsen K, Deville JG (2006) Clearance of Cellulosimicrobium cellulans bacteremia in a child without central venous catheter removal. J Clin Microbiol 44:2650-4. doi:10.1128/JCM.02485-05

25. Lo S-C, Li B, Hung G-C, Lei H, Li T, Zhang J et al (2013) Isolation and characterization of two novel bacteria Afipia cberi and Mesorhizobium hominis from blood of a patient afflicted with fatal pulmonary illness. PLoS One 8(12):e82673. doi:10.1371/journal. pone. 0082673

26. Lo S-C, Hung G-C, Li B, Lei H, Li T, Nagamine K et al (2015) Mixed group of Rhizobiales microbes in lung and blood of a patient with fatal pulmonary illness. Int J Clin Exp Pathol 8:13834-52

27. Salter SJ, Cox MJ, Turek EM, Calus ST, Cookson WO, Moffatt MF et al (2014) Reagent and laboratory contamination can critically impact sequence-based microbiome analyses. BMC Biol 12:87. doi:10.1186/s12915-014-0087-z

28. Laurence M, Hatzis C, Brash DE (2014) Common contaminants in next-generation sequencing that hinder discovery of lowabundance microbes. PLoS One 9(5):e97876. doi:10. 1371/journal.pone.0097876

29. Sivan A, Corrales L, Hubert N, Williams JB, Aquino-Michaels K, Earley ZM et al (2015) Commensal Bifidobacterium promotes antitumor immunity and facilitates anti-PD-L1 efficacy. Science 350:1084-9. doi:10.1126/science.aac4255

30. Turroni F, Taverniti V, Ruas-Madiedo P, Duranti S, Guglielmetti S, Lugli GA et al (2014) Bifidobacterium bifidum PRL2010 modulates the host innate immune response. Appl Environ Microbiol 80: 730-40. doi:10.1128/AEM.03313-13

31. Fanning S, Hall LJ, Cronin M, Zomer A, MacSharry J, Goulding D et al (2012) Bifidobacterial surface-exopolysaccharide facilitates commensal-host interaction through immune modulation and pathogen protection. Proc Natl Acad Sci USA 109:2108-13. doi:10.1073/pnas.1115621109

32. Shimizu K, Ogura H, Asahara T, Nomoto K, Matsushima A, Hayakawa $\mathrm{K}$ et al (2015) Gut microbiota and environment in patients with major burns - a preliminary report. Burns 41:e28-33. doi:10.1016/j.burns.2014.10.019

33. Romond M-B, Colavizza M, Mullié C, Kalach N, Kremp O, Mielcarek C et al (2008) Does the intestinal bifidobacterial colonisation affect bacterial translocation? Anaerobe 14:43-8. doi:10.1016/j.anaerobe.2007.09.003

34. Reddy BS, MacFie J, Gatt M, Macfarlane-Smith L, Bitzopoulou K, Snelling AM (2007) Commensal bacteria do translocate across the intestinal barrier in surgical patients. Clin Nutr 26:208-15. doi:10.1016/j.clnu.2006.10.006

35. Shin N-R, Whon TW, Bae J-W (2015) Proteobacteria: microbial signature of dysbiosis in gut microbiota. Trends Biotechnol 33: 496-503. doi:10.1016/j.tibtech.2015.06.011 